\title{
Morphological and Structural Changes on Human Dental Enamel After Er:YAG Laser Irradiation: AFM, SEM, and EDS Evaluation
}

\author{
Laura Emma Rodríguez-Vilchis, D.D.S., M.S.D., Rosalía Contreras-Bulnes, D.D.S., Ph.D., \\ Oscar Fernando Olea-Mejìa, CH.E., Ph.D., ${ }^{2}$ Ignacio Sánchez-Flores, D.D.S., M.S.D., Ph.D., \\ and Claudia Centeno-Pedraza, D.D.S., M.S.D.
}

\begin{abstract}
Objective: The purpose of this study was to evaluate, using atomic force microscopy (AFM), scanning electron microscopy (SEM) and energy dispersive $X$-ray spectroscopy (EDS), the morphological and structural changes of the enamel after irradiation with the Er:YAG laser. Background data: A previous study showed that subablative Er:YAG laser irradiation produced undesirable morphological changes on the enamel surface, such as craters and cracks; however, the enamel acid resistance was not increased. Methods: Fifty-two samples of human enamel were divided into four groups $(n=13)$ : Group I was the control (no laser irradiation), whereas Groups II, III, and IV were irradiated with the Er:YAG $100 \mathrm{~mJ}\left(12.7 \mathrm{~J} / \mathrm{cm}^{2}\right), 100 \mathrm{~mJ}\left(7.5 \mathrm{~J} / \mathrm{cm}^{2}\right)$, and $150 \mathrm{~mJ}\left(11 \mathrm{~J} / \mathrm{cm}^{2}\right)$, respectively, at $10 \mathrm{~Hz}$ with water spray. The morphological changes were observed by AFM and SEM. The weight percentages $(w t \%)$ of calcium $(\mathrm{Ca})$, phosphorus $(\mathrm{P})$, oxygen $(\mathrm{O})$ and chlorine $(\mathrm{Cl})$ were determined in the resultant craters and their periphery using EDS. Kruskal-Wallis and Mann-Whitney $U$ tests were performed $(p \leq 0.05)$ to distinguish significant differences among the groups. Results: The AFM images showed cracks with depths between $250 \mathrm{~nm}$ and $750 \mathrm{~nm}$ for Groups II and IV, respectively, and the widths of these cracks were $5.37 \mu \mathrm{m}$ and $2.58 \mu \mathrm{m}$. The interior of the cracks showed a rough surface. The SEM micrographs revealed morphological changes. Significant differences were detected in $\mathrm{Ca}, \mathrm{P}$, and $\mathrm{Cl}$ in the crater and its periphery. Conclusions: AFM observations showed triangular-shaped cracks, whereas craters and cracks were evident by SEM in all irradiated samples. It was not possible to establish a characteristic chemical pattern in the craters.
\end{abstract}

\section{Introduction}

$\mathrm{T}$ He ER:YAG LASER IS WELL ABSORBED by all biological tissues that contain water molecules. In dentistry, this laser is prescribed not only for the treatment of soft tissues but also for the ablation of hard ones. ${ }^{1}$ A mechanism of biological tissue ablation with the Er:YAG laser has been proposed that is based on the optical properties of its emission wavelength and the morphological features of the surface ablated by the Er:YAG laser. During irradiation, the laser's energy is absorbed selectively by water molecules and hydrous organic components of the biological tissues, which causes the evaporation of water and organic components, resulting in thermal effects caused by the heat generated by this process (called "photothermal evaporation"). Moreover, in hard-tissue pro- cedures, the water vapor production induces an increase of the internal pressure within the tissue, resulting in an explosive expansion called a "microexplosion" 2,3 that produces changes in the morphology of the enamel, ${ }^{4-8}$ including undesirable effects that have been described as craters and cracks. $^{9-14}$

Furthermore, the results in the available literature regarding subablative Er:YAG laser irradiation as a method to increase enamel acid resistance for caries prevention have been contradictory. ${ }^{15,16}$ One previous study evaluated enamel morphological changes and acid resistance after subablative Er:YAG laser irradiation. Although the acid resistance was not increased, scanning electron microscopy (SEM) analysis on the enamel surface showed craters and cracks, ${ }^{17}$ which may be sites of high risk sites for bacterial

\footnotetext{
${ }^{1}$ Centro de Investigación y Estudios Avanzados en Odontología de la Facultad de Odontología de la Universidad Autónoma del Estado de México, Toluca, Estado de México, México.

${ }^{2}$ Centro Conjunto de Investigación en Química Sustentable UAEM-UNAM, Facultad de Química UAEM, Carretera Toluca-Atlacomulco, Toluca, Estado de México, México.
} 
accumulation. In addition, a massive demineralization along the cracks has been reported. ${ }^{15}$ However, additional research regarding the undesirable effects of Er:YAG laser irradiation is needed.

Recently, more attention has been focused on the application of atomic force microscopy (AFM) in dental research $^{18-21}$ because of its applications in the exploration of biomaterial surfaces. Furthermore, it is useful because it has a higher resolution than SEM, and a three-dimensional image compared with the two-dimensional image of a sample observed with SEM. The use of both microscopic analyses may improve the observation of morphological changes of the enamel, resulting in a synergism achieved by the advantages of each technique.

Regarding enamel structural changes associated with Er:YAG laser irradiation, alterations to apatitic inorganic component of tooth enamel, ${ }^{22}$ as well as differences in the calcium/phosphorus $(\mathrm{Ca} / \mathrm{P})$ ratio, $^{13}$ and significant laserinduced reduction of carbonate and modification of organic material content, have been reported. ${ }^{23}$

Therefore, the aim of the present study was to evaluate, using AFM and SEM, the morphological changes of the enamel surface after irradiation with the Er:YAG laser, and the structural changes through the weight percentages $(w t \%)$ of $\mathrm{Ca}, \mathrm{P}$, oxygen $(\mathrm{O})$ and chlorine $(\mathrm{Cl})$ in the resulting craters and periphery area with energy dispersive $\mathrm{X}$-ray spectroscopy (EDS).

\section{Materials and Methods}

\section{Tooth selection and sample preparation}

The study protocol was reviewed and approved by the Research and Ethics Committee at the Autonomous University of the State of Mexico (UAEM). All subjects enrolled in this research signed a consent form. Five unerupted permanent third molar teeth extracted from two patients for therapeutic reasons were stored in a 0.1 (wt/vol) thymol solution at $4{ }^{\circ} \mathrm{C}$ until the experiment was performed. The crown was separated from the root in each tooth using a diamond disc (BesQual, NewYork, NY) mounted on a lowspeed motor (Brasseler, Savannah, GA) under distilled water irrigation to prevent dehydration. The crown was fixed to a glass slide with thermoplasticized epoxy resin (Allied, Rancho Dominguez, CA).

Afterward, a diamond wheel (South Bay Technology, Inc., San Clemente, CA) mounted on a cutter (South Bay Technology, Inc.) was employed to obtain the samples under constant irrigation. For the AFM evaluation, an unerupted permanent third molar was vertically crosscut in the buccolingual direction, and four samples measuring $8 \mathrm{~mm}$ wide $\mathrm{x}$ $5 \mathrm{~mm}$ high were obtained (one for each group). The samples were fixed with thermoplastic cement (Buehler, Lake Bluff, IL) to AFM steel mounting discs (SPI Supplies, West Chester, PA). All of the samples were polished with a MetaServ ${ }^{\circledR} 2000$ polisher machine (Buehler), using diamond lapping film with grain sizes of $35,30,15,9,6,3,1,0.5,0.25$, and $0.1 \mu \mathrm{m}$ under constant water irrigation. Only two samples (Groups II and III) were further polished after laser irradiation.

For the EDS and SEM analysis, the occlusal surfaces from four unerupted permanent third molar teeth were vertically crosscut in the buccolingual and mesiodistal directions. Twelve samples per molar were obtained (three for each group), measuring $1.5 \mathrm{~mm}$ wide $\times 2 \mathrm{~mm}$ in length. A total of 48 samples were obtained (twelve samples per group) (Fig. 1).

Finally, all of the samples were rinsed with deionized water and dried at room temperature for AFM, EDS, and SEM evaluation.

\section{Er:YAG laser irradiation}

An Er:YAG laser system (Lumenis OPUS DUO ${ }^{\mathrm{TM}}$ Er: YAG $+\mathrm{CO}_{2}$, Yokneam, Israel) was used to irradiate the samples. The main experimental parameters of the laser during the study were as follows: wavelength fixed at $2.94 \mu \mathrm{m}$, energy pulse from 100 to $150 \mathrm{~mJ}$, frequency of $10 \mathrm{~Hz}$, pulse duration of $250-400 \mu \mathrm{sec}$, and an exit tip diameter from 1.0 to $1.3 \mathrm{~mm}$. Fifty-two enamel samples were divided into four groups $(n=13)$ (Table 1$)$.

Energy levels were calibrated using the calipers of the equipment, and the energy delivered was measured periodically with a power meter (LaserMate-P, Coherent Co., Santa Clara, CA). The irradiation was manually performed in one direction such that the tips were smoothly scanned perpendicularly to the samples' enamel surface while distilled water was sprayed $(5.0 \mathrm{~mL} / \mathrm{min})$ to reduce heating. Each sample was irradiated only once during $18 \mathrm{sec}$, while the tip-sample distance was kept at a fixed position of $1 \mathrm{~mm}$. A sheet of stainless steel $(23 \mathrm{~mm} \times 5 \mathrm{~mm} \times 0.5 \mathrm{~mm})$ was fixed to the top of the laser handpiece to perform this task. At that tip-sample distance, the exit tip and the laser beam had the same diameter, as corroborated with a laminated infrared sensor screen (Lumitek International, Inc., Ijamsville, MD).

\section{AFM}

AFM images of four samples (three irradiated and one control) were recorded using a Digital Instruments Multimode NanoScope IIIa (Digital Instruments, Plainview, NY) operating in contact mode and using a standard $\mathrm{Si}_{3} \mathrm{~N}_{4}$ tip.

\section{EDS}

Forty-eight samples (12 per group) were dried at room temperature and attached to a testing ring with an adhesive carbon tape (SPI Supplies, West Chester, PA) to determine the weight percentage $\left(\mathrm{wt}_{\mathrm{t}} \%\right.$ ) of $\mathrm{Ca}, \mathrm{P}, \mathrm{O}$ and $\mathrm{Cl}$ in the resulting

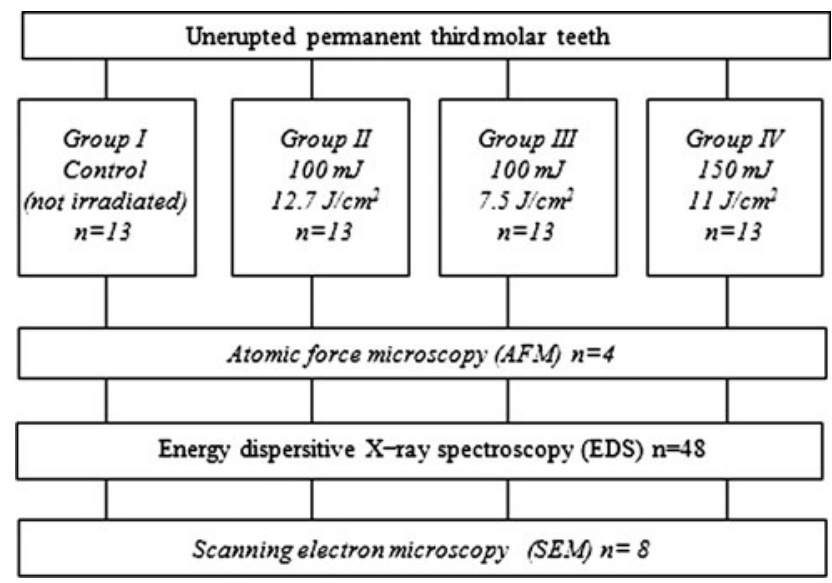

FIG. 1. Experimental design. 
Table 1. Experimental and Control Groups

\begin{tabular}{lccr}
\hline Groups & $\begin{array}{c}\text { Energy } \\
\text { output }\end{array}$ & $\begin{array}{l}\text { Diameter } \\
\text { of the Tip }\end{array}$ & $\begin{array}{r}\text { Energy } \\
\text { density }\end{array}$ \\
\hline I (Control) & & & \\
II & $100 \mathrm{~mJ}$ & $1.0 \mathrm{~mm}$ & $12.7 \mathrm{~J} / \mathrm{cm}^{2}$ \\
III & $100 \mathrm{~mJ}$ & $1.3 \mathrm{~mm}$ & $7.5 \mathrm{~J} / \mathrm{cm}^{2}$ \\
IV & $150 \mathrm{~mJ}$ & $1.3 \mathrm{~mm}$ & $11.0 \mathrm{~J} / \mathrm{cm}^{2}$ \\
\hline
\end{tabular}

craters and their periphery by EDS (ThermoNoran Superdry, Thermo Scientific, Waltham, MA), under the following parameters: $15.0 \mathrm{KeV}$ and $100 \mathrm{sec}$ livetime. By this method, 12 points were performed per sample.

\section{SEM}

Eight samples (two per group) were attached to a testing ring using an adhesive carbon paper and were gold-coated (Vacuum Evaporator JEOL, Tokyo, Japan) for observation using the scanning electron microscope (JSM-5300, JEOL).

\section{Statistical analysis}

All data were analyzed using the SPSS 13.0 statistical package for Windows (SPSS Inc., Chicago, IL). The measurements were analyzed using the Kolmogorov-Smirnov test at a $p \leq 0.05$ level of significance to assess the distribution of the data. The Kruskal-Wallis and Mann-Whitney $U$ tests were used with a level of significance of $p \leq 0.05$.

\section{Results}

\section{AFM surface analysis}

Group I control (no laser irradiation). AFM images show the typical enamel surface of the polished sample (Fig. 2a and $b)$.

Group II. A crack $(\sim 250 \mathrm{~nm}$ deep $\times 2.58 \mu \mathrm{m}$ wide $\times 20 \mu \mathrm{m}$ long) can be easily observed on the enamel sur- face; it is marked by two red triangles or cursors. (Fig. 3a and $b$ ).

Group III. There is an S-shaped crack across the AFM top view image. The marked segment between the red cursors is $\sim 500 \mathrm{~nm}$ deep $\times 2.22 \mu \mathrm{m}$ wide $\times 20 \mu \mathrm{m}$ long (Fig. $4 \mathrm{a}$ ). The 3-D expression shows a very rough surface characterized by ridges and grooves (Fig. $4 \mathrm{~b}$ ).

Group IV. The AFM top view image shows a curved crack $\sim 750 \mathrm{~nm}$ deep $\times 5.37 \mu \mathrm{m}$ wide $\times 20 \mu \mathrm{m}$ long, in an unpolished sample after enamel irradiation (Fig. 5a). The 3-D figure shows the stacking of removed material at both sides of the crack, caused by laser irradiation (Fig. 5b). The area inside the fissure shows an evident rough surface (Fig. 5c).

\section{EDS evaluation}

The experimental data obtained by EDS for all groups, in the crater and periphery with respect to $w \mathrm{t} \%$ of $\mathrm{Ca}, \mathrm{P}, \mathrm{O}$ and $\mathrm{Cl}$, are presented in Table 2. When the Kruskal-Wallis test was applied, statistically significant differences were obtained for $\mathrm{Ca}(p=0.001), \mathrm{P}(p=0.004)$ and $\mathrm{Cl}(p=0.003)$. According to the Mann-Whitney $U$ test, the following statistically significant differences were found. For Ca, Groups III and IV demonstrated values in the crater and the periphery, respectively, that differed from what was found in all of the groups and areas studied. Additionally, in the periphery, Group III showed the lowest $\mathrm{wt} \%$ of $\mathrm{Ca}$ when compared with the control group. Regarding P, the periphery of Group IV had the lowest value among all of the groups and study areas. The results obtained for $\mathrm{Cl}$ revealed differences in the crater when comparing the different groups and areas.

\section{SEM surface analysis}

The most significant images obtained for each group are shown. The control group (not irradiated) displayed open enamel prisms, and the rest of the surface was predominantly
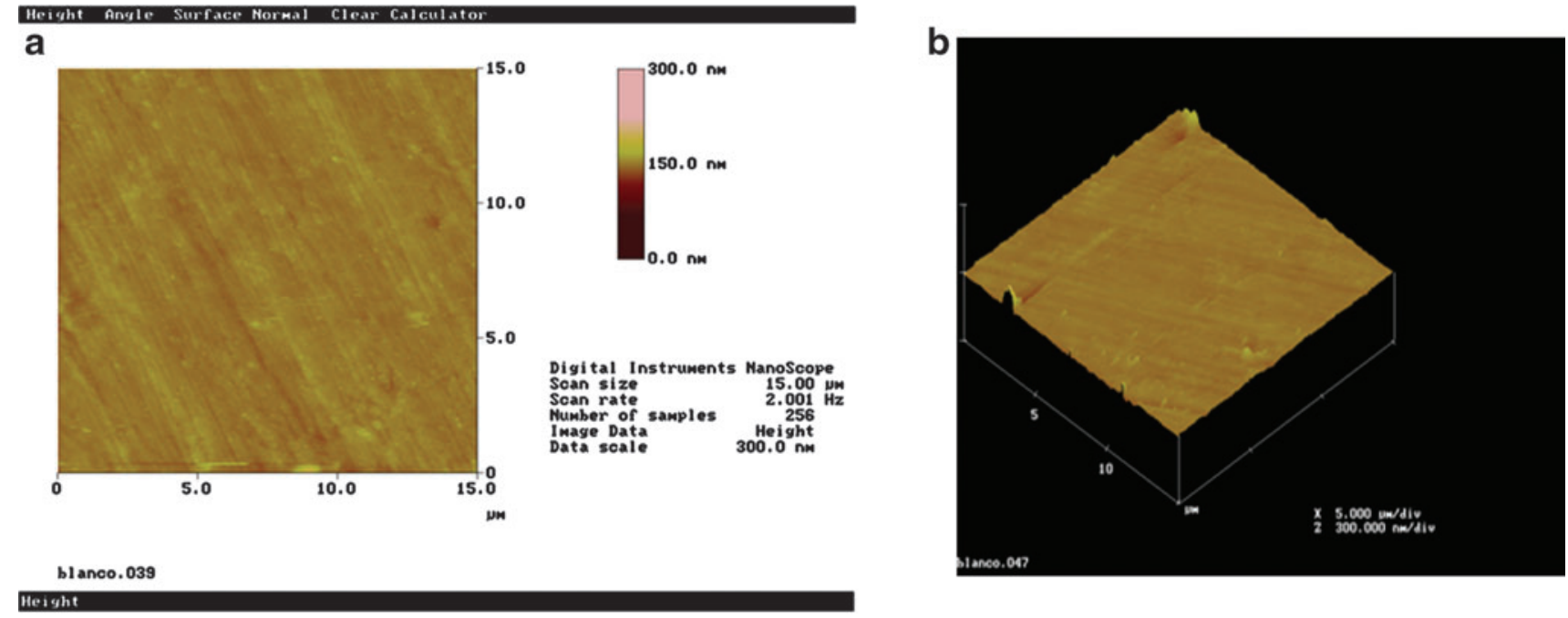

FIG. 2. Tapping mode AFM images of the control group: (a) Top view mode and (b) 3-D figure of $15 \times 15 \mu \mathrm{m}^{2}$ untreated enamel polished area. 

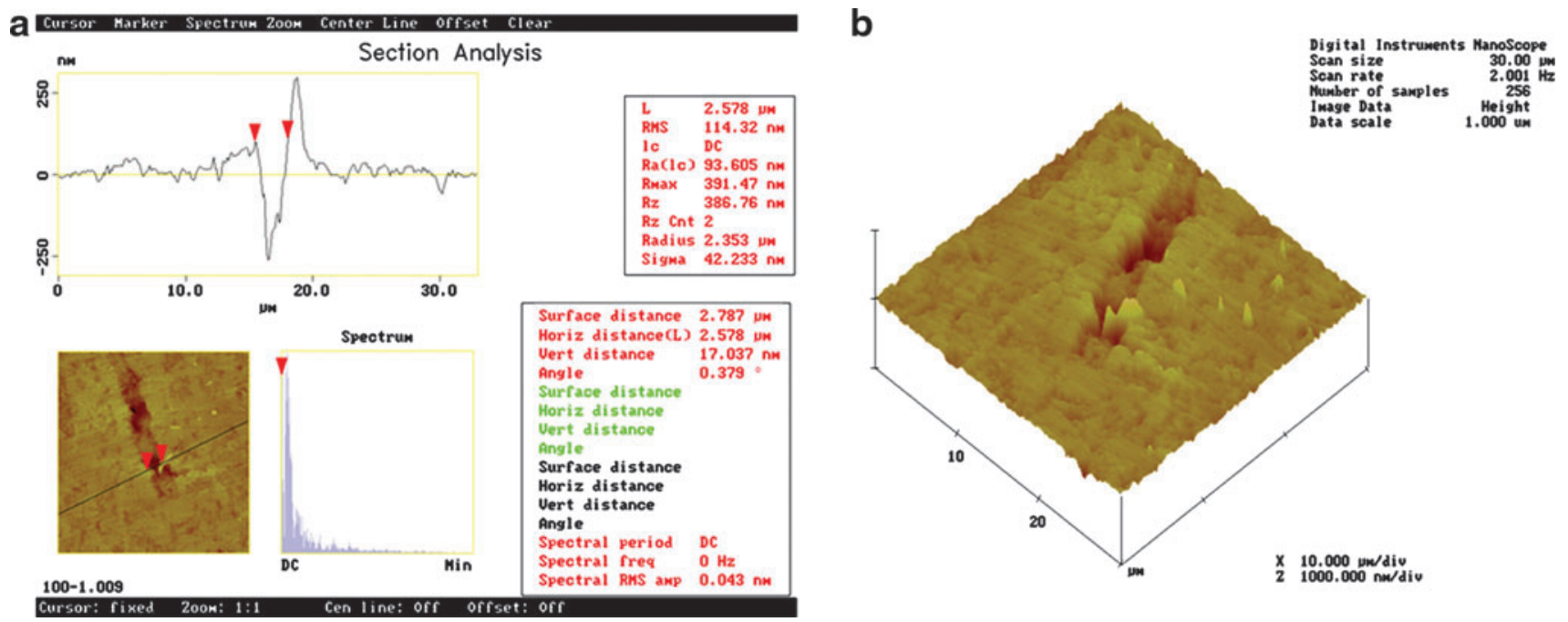

FIG. 3. AFM images of $30 \times 30 \mu \mathrm{m}$ from the Er:YAG laser-irradiated enamel at $100 \mathrm{~mJ} / 10 \mathrm{~Hz}, 12.7 \mathrm{~J} / \mathrm{cm}^{2}$ after polishing. Section analysis and (a) top view image mode and (b) 3-D figure are shown.

smooth (Fig. 6). In the irradiated samples (Figs. 7, 8, and 9), rough areas, craters, and cracks were observed; in addition, in the regions near the craters, occluded prisms were observed in the smooth zones.

\section{Discussion}

It has been reported ${ }^{4-14}$ that Er:YAG laser irradiation induces morphological changes in the enamel that include the formation of rough surfaces, cracks, and craters, which seem to be more prone to bacterial accumulation. Such morphological changes create favorable conditions for the development of carious lesions. ${ }^{15}$ On the other hand, an increase in enamel acid resistance associated with Er:YAG laser irradiation of smooth surfaces has been suggested by several authors. ${ }^{10,11,13}$ The results from a previous study ${ }^{17}$ pointed out that the used subablative energy density did not promote an increase in the acid resistance of the occlusal enamel surface. In contrast, evident enamel morphological changes were found by SEM evaluation.

In order to further study the morphology and chemical characterization of these undesirable effects, the samples investigated in the actual study were irradiated under the same conditions used in a previous work, which were based on observations from pilot studies.

In this study, both SEM and AFM techniques, which are widely used in materials science, were chosen to evaluate the samples' morphology. Furthermore, SEM has been widely used in dentistry, whereas AFM has only recently been introduced to this discipline and is rarely applied to the study of enamel morphological changes produced by irradiation with any type of laser. Both techniques have advantages and a

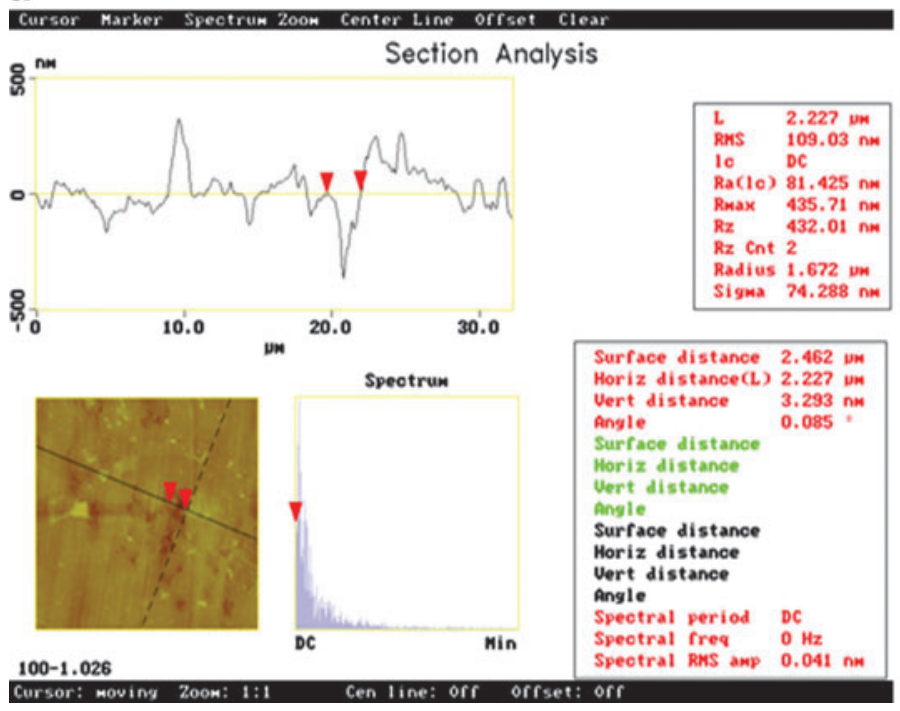

b

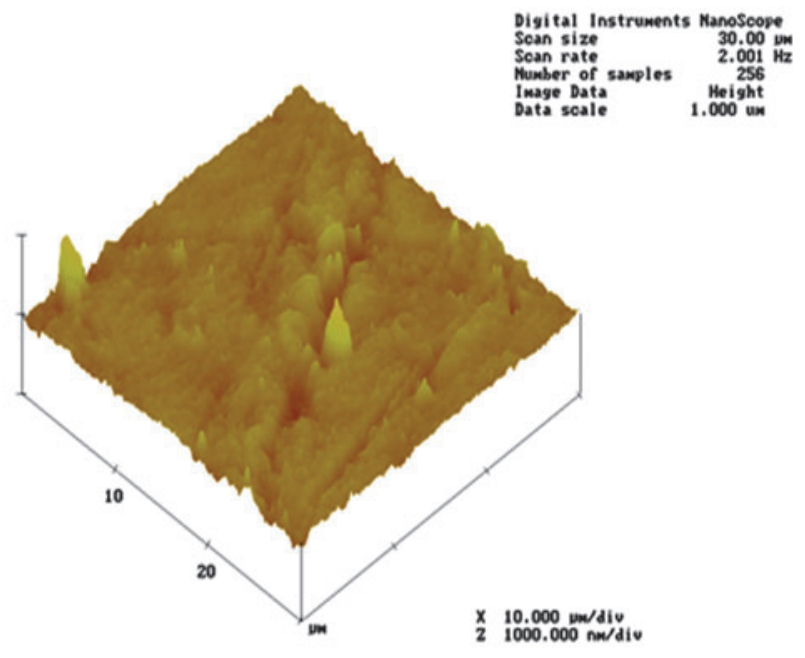

FIG. 4. AFM images after Er:YAG laser irradiation at $100 \mathrm{~mJ} / 10 \mathrm{~Hz}, 7.5 \mathrm{~J} / \mathrm{cm}^{2}$, and polishing. Section analysis and (a) top view image mode and (b) 3-D figure are shown. 


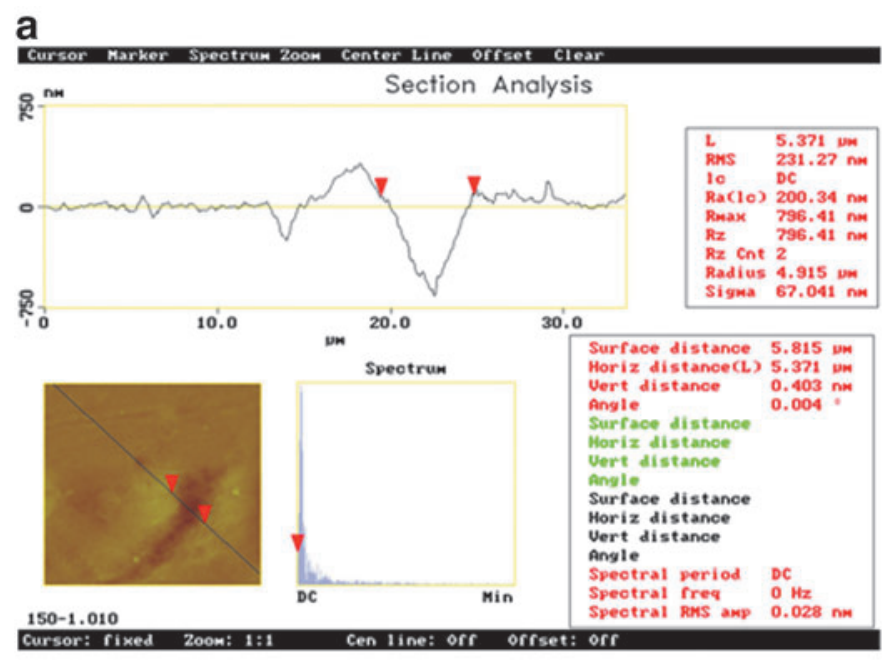

b
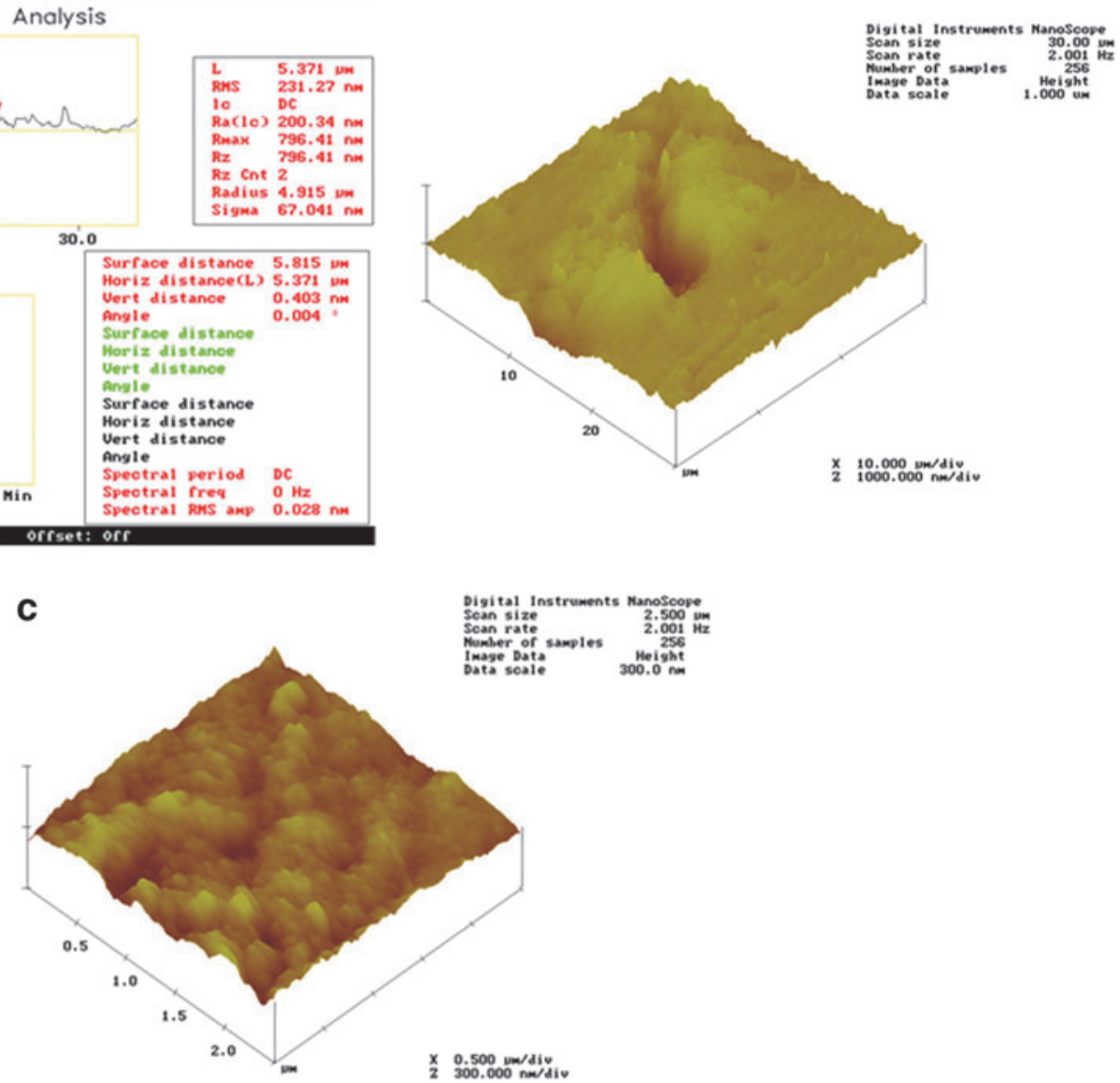

FIG. 5. (a and b) AFM images after Er:YAG laser irradiation at $150 \mathrm{~mJ} / 10 \mathrm{~Hz}, 11 \mathrm{~J} / \mathrm{cm}^{2}$, and (c) the AFM image obtained from the interior of the fissure.

disadvantages and they are complementary to each other. There are two main advantages of SEM versus AFM: first, one can observe samples almost without any sample preparation (other than the gold coating that is desired for high resolution images, which is not always needed) and second, one can obtain the chemical composition of a sample if the microscope is provided with an EDS detector. On the other hand, the main advantage of AFM is that one can not only obtain the surface morphology (as in SEM images) but also information in three dimensions, which makes it especially useful to measure heights of particles, valleys, and cracks.
For this reason, AFM was used to obtain 3D images of the crack produced in the enamel surface by Er:YAG laser irradiation. A detailed analysis of the cracks suggested that these defects show a triangular shape with a greater width than depth and with the base of the triangle oriented toward the irradiated surface, an apex in the bottom and a rough internal surface. These characteristics are more evident in the 3D image obtained from inside a crack in Group IV. Although the studied cracks had different widths and depths, it was not possible to establish a correlation between the employed irradiation conditions and the crack dimensions; consequently, additional studies are needed. The 3D image

Table 2. Mean Values and Standard Deviations of Weight Percentages for Each Element of the Crater and Periphery on the Enamel Surface

\begin{tabular}{|c|c|c|c|c|c|c|c|c|c|}
\hline Group & $\mathrm{N}$ & \multicolumn{2}{|c|}{$\mathrm{Ca}$} & \multicolumn{2}{|c|}{$P$} & \multicolumn{2}{|c|}{$O$} & \multicolumn{2}{|c|}{$\mathrm{Cl}$} \\
\hline Control & 12 & \multicolumn{2}{|c|}{$31.4 \pm 3.5^{\mathrm{A}}$} & \multicolumn{2}{|c|}{$17.3 \pm 2.3^{\mathrm{A}}$} & \multicolumn{2}{|c|}{$44.4 \pm 3.3^{\mathrm{A}}$} & \multicolumn{2}{|c|}{$0.6 \pm 0.1^{\mathrm{A}, \mathrm{C}}$} \\
\hline $\begin{array}{l}\text { Experimental } \\
\text { groups }\end{array}$ & $\mathrm{N}$ & Crater & Periphery & Crater & Periphery & Crater & Periphery & Crater & Periphery \\
\hline II & 12 & $33.4^{\mathrm{A}, \mathrm{C}} \pm 7.6$ & $33.3^{\mathrm{A}, \mathrm{C}} \pm 10.1$ & $17.1^{\mathrm{A}} \pm 2.6$ & $16.6^{\mathrm{A}} \pm 1.6$ & $44.2^{\mathrm{A}} \pm 10.0$ & $42.5^{\mathrm{A}} \pm 13.3$ & $0.6^{\mathrm{A}, \mathrm{B}} \pm 0.1$ & $0.6^{\mathrm{A}, \mathrm{C}} \pm 0.1$ \\
\hline III & 12 & $41.1^{\mathrm{B}} \pm 12.2$ & $30.4^{\mathrm{C}} \pm 4.1$ & $17.5^{\mathrm{A}} \pm 1.9$ & $17.9^{\mathrm{A}} \pm 1.7$ & $38.4^{\mathrm{A}} \pm 12.5$ & $47.8^{\mathrm{A}} \pm 5.8$ & $0.7^{\mathrm{B}} \pm 0.1$ & $0.5^{\mathrm{A}, \mathrm{C}} \pm 0.2$ \\
\hline IV & 12 & $29.2^{\mathrm{A}, \mathrm{C}} \pm 4.8$ & $25.0^{\mathrm{D}} \pm 5.0$ & $17.0^{\mathrm{A}} \pm 2.1$ & $* 13.9^{\mathrm{B}} \pm 2.1$ & $49.9^{\mathrm{A}} \pm 6.8$ & $47.3^{\mathrm{A}} \pm 10.9$ & $0.6^{\mathrm{A}, \mathrm{B}} \pm 0.1$ & $0.5^{\mathrm{C}} \pm 0.1$ \\
\hline
\end{tabular}

${ }^{*}$ Groups with different letters are significantly different $(p \leq 0.05)$, statistical analysis by element. 


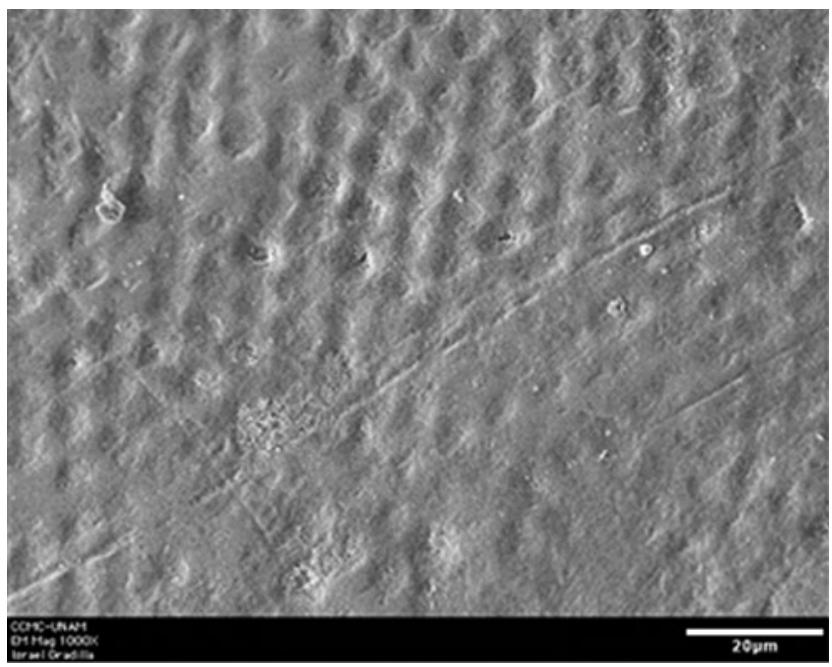

FIG. 6. Representative SEM micrograph of samples from the control group showing occluded prisms and a smooth area (original magnification $\times 1000$ ); scale bar $=20 \mu \mathrm{m}$.

and cross-section analysis showed an evident stacking of material on the surface around the crack when the sample was not polished after laser irradiation, resulting in an apparently deeper and wider defect. This stacking phenomenon has not been reported in previous SEM studies, suggesting that AFM may be a useful tool to study more thoroughly the morphological characteristics of the enamel surface after Er:YAG laser irradiation. Considering that the average radius of Streptococcus mutans is $0.321 \pm 0.007 \mu \mathrm{m},{ }^{24}$ the dimensions of the cracks and their internal rough surface shown in the 3D profile could be favorable sites for the accumulation of cariogenic bacteria such as $S$. mutans.

Regarding the SEM observations, non-irradiated samples (Group I) showed mainly exposed and closed prisms as well as smooth surfaces. Furthermore, all of the irradiated sam-

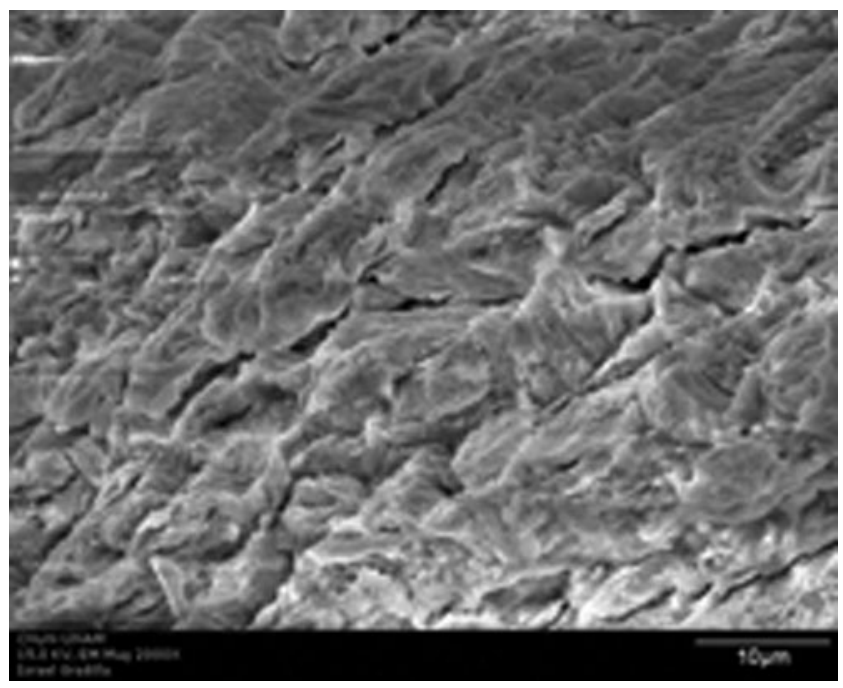

FIG. 7. SEM micrograph of the enamel surface after Er:YAG laser irradiation at $100 \mathrm{~mJ} / 10 \mathrm{~Hz}, 12.7 \mathrm{~J} / \mathrm{cm}^{2}$ (original magnification $\times 2000$ ); scale $\mathrm{bar}=10 \mu \mathrm{m}$. A crack is evident crossing the central area of the surface.
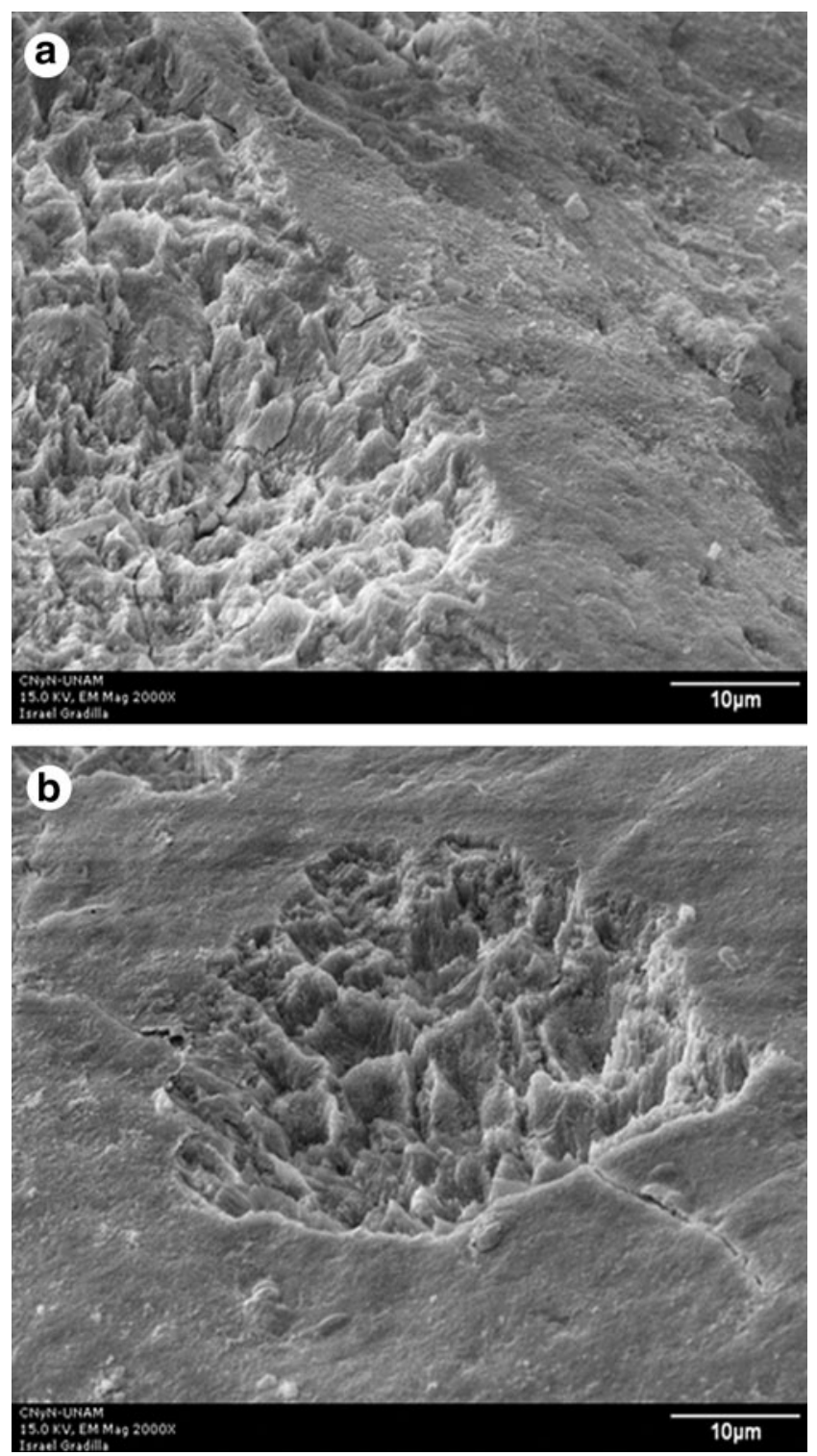

FIG. 8. SEM micrograph of the enamel surface after Er: YAG laser irradiation at $100 \mathrm{~mJ} / 10 \mathrm{~Hz}, 7.5 \mathrm{~J} / \mathrm{cm}^{2}$ (original magnification $\times 2000$ ); scale bar $=60 \mu \mathrm{m}$. (a) Typical image of a crater produced by irradiation. (b) Smooth enamel surface surrounding a crater.

ples displayed rough areas, craters, and cracks, consistent with the results of previous studies. ${ }^{4-9}$

The use of SEM has provided relevant findings for the study of enamel morphological changes after laser irradiation. However, the addition of EDS as an analytical technique provides valuable information about the chemical changes on the irradiated enamel surface. Considering that the craters could be zones more susceptible to caries development because of their morphology (evident changes inside the crater and less pronounced in the outer area) it is important to determinate their chemical composition.

The EDS analysis revealed differences within the groups, depending upon the studied area, as well as among the groups, whereas it has been reported that laser treatment did not affect the mean percentage weights of $\mathrm{Ca}$ and $\mathrm{P}$, or the 

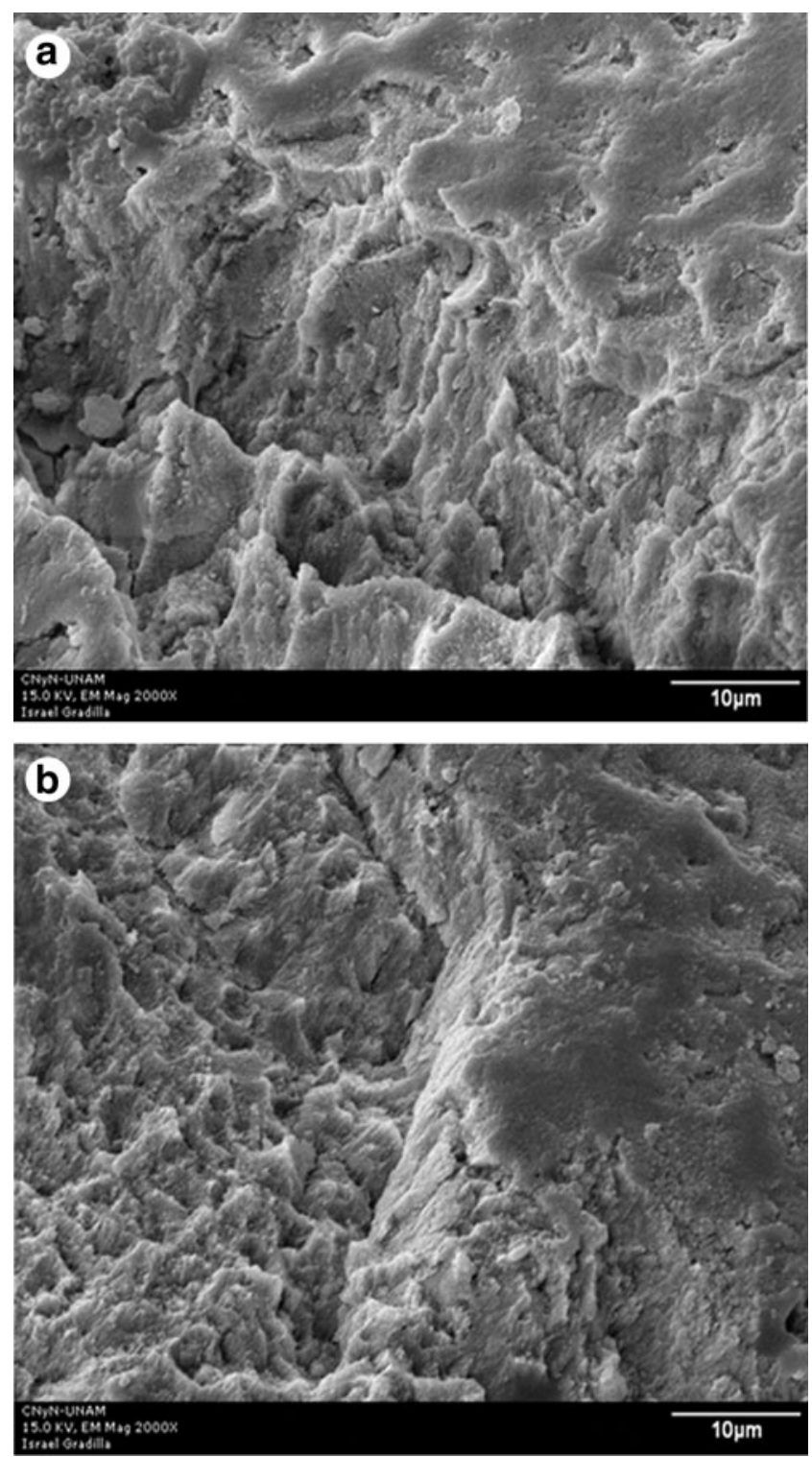

FIG. 9. (a and b) SEM micrograph of the enamel surface after Er:YAG laser irradiation at $150 \mathrm{~mJ} / 10 \mathrm{~Hz}, 11 \mathrm{~J} / \mathrm{cm}^{2}$ (original magnification $\times 2000$ ); scale bar $=10 \mu \mathrm{m}$.

$\mathrm{Ca} / \mathrm{P}$ ratio on the enamel surface. ${ }^{25}$ However, $\mathrm{X}$-ray photoelectron spectroscopy (XPS) analysis reported that the binding energies of $\mathrm{Ca} 2 \mathrm{p}$ and $\mathrm{P} 2 \mathrm{p}$ of Er:YAG laser-irradiated bovine enamel were slightly different from those of control group. ${ }^{22}$

Regarding the $w \mathrm{t} \%$ of the studied elements, only $\mathrm{O}$ showed similar values among studied groups and areas. For $\mathrm{Ca}$, there was no change in the $\mathrm{wt} \%$ among groups and studied areas when higher energy density was used, suggesting that a lower energy density is a factor associated with the increase in $\mathrm{Ca} w \mathrm{t} \%$, which could increase acid resistance to bacterial attack despite crater morphology. A tendency to $\mathrm{P}$ wt\% stability was observed, but additional research is necessary to confirm it. Moreover, chemical changes, such as the reduction of phosphorus in the periphery area of the craters of Group IV, could increase the risk of development of carious lesions because of the important role played by phosphate ions in the demineralization-remineralization process of hydroxyapatite crystals.

Regarding $\mathrm{Cl} w \mathrm{t} \%$, no significant difference between the crater and the periphery was observed when the highest energy density was used for Er:YAG laser irradiation, consistent with the findings of $\mathrm{Ca}$ and $\mathrm{O}$, suggesting that this energy density only produces morphological changes on the enamel without structural variations. The differences found among groups and areas could be explained by atomic substitution in apatite, specifically chlorapatite (ClAp), as might be expected from the difference in electronegativities of the elements and the heat generated, which promotes atomic substitution, ${ }^{26}$ specifically the temperature produced by lower energy densities of laser irradiation as used in Groups III and IV. Nevertheless, additional research is needed to confirm this hypothesis.

\section{Conclusions}

AFM observations revealed cracks characterized by a triangular shape with a greater width than depth and with their bases oriented toward the irradiated surface. Also, internal surfaces of the cracks were rough, and it was not possible to establish a clear tendency of the chemical changes observed inside and in the periphery of the craters. Finally, additional research is necessary to clarify the probable influence of the irradiation conditions on the morphology and chemical composition of the cracks and craters.

\section{Acknowledgments}

We thank Dr. Enrique Samano for his valuable support and Israel Gradilla for technical assistance, both from the Centro de Nanociencias y Nanotecnología, Universidad Nacional Autónoma de México (UNAM), and David Villanueva Jurado and Gerardo Guadarrama Álvarez, maxillofacial surgeons from the School of Dentistry, Universidad Autónoma del Estado de México (UAEM), for their assistance with obtaining the samples. This project was financed by UAEM and UNAM.

\section{Author Disclosure Statement}

No conflicting financial interests exist.

\section{References}

1. Aoki, A., Sasaki, K.M., Watanabe, H., and Ishikawa, I. (2000). Lasers in nonsurgical periodontal therapy. J. Periodontol. 36, 59-97.

2. Hibst, R., and Keller, U. (1989). Experimental studies of the application of the Er:YAG laser on dental hard substances: I. Measurement of the ablation rate. Lasers Surg. Med. 9, 338344.

3. Keller, U., and Hibst, R. (1989). Experimental studies of the application of the Er:YAG laser on dental hard substances: II Light microscopic and SEM investigations. Lasers Surg. Med. 9, 345-351.

4. Souza-Gabriel, A.E., Chinelatti, M.A., Borsatto, M.C., Pecora, J.D., Palma-Dibb, R.G., and Corona S.A.M. (2008). SEM analysis of enamel surface treated by Er:YAG laser: Influence of irradiation distance. Microsc. Res. Tech. 71, 536-541.

5. Freitas, P.M., Navarro, R.S., Barros, J.A., and Eduardo, C.D.P. (2007). The use of Er:YAG laser for cavity preparation: An SEM evaluation. Microsc. Res. Tech. 70, 803-808. 
6. Delmé, K.I.M., and De Moor R.J.G. (2007). Scanning electron microscopic evaluation of enamel and dentine surfaces after Er:YAG laser preparation and laser conditioning. Photomed. Laser Surg. 25, 393-401.

7. Correa-Alfonso, A.M., Palma-Dibb,R.G., and Pecora, J.D. (2010). Composite filling removal with erbium:yttriumaluminum-garnet laser: morphological analyses. Lasers Med. Sci. 25, 1-7.

8. Navarro, R.S., Gouw-Soares, S. Cassoni A., Haypec P., Zezell D.M., and Eduardo, C.D. (2010). The influence of erbium: yttrium-aluminum-garnet laser ablation with variable pulse width on morphology and microleakage of composite restorations. Lasers Med Sci. 25, 881-889.

9. Tokonabe, H., Kouji R., Watanave, H., Nakamura, Y., and Matsumoto k. (1999). Morphological changes of human teeth with Er:YAG laser irradiation. J. Clin. Laser. Med. Surg. 20, 27-35.

10. Cecchini, R.C.M., Zezell, D.M., de Oliveira, E., de Freitas, P.M., and Eduardo C.D. (2005). Effect of Er:YAG laser on enamel acid resistance: Morphological and atomic spectrometry analysis. Lasers Surg. Med. 37, 366-372.

11. Apel, C., Meister, J., Gotz, H., Duschner, H., and Gutknecht, N. (2005). Structural changes in human dental enamel after subablative erbium laser irradiation and its potential use for caries prevention. Caries Res. 39, 65-70.

12. Matson, J.R., Matson, E., Navarro, R.S., Bocangel, J.S., Jaeger, R.G., and Eduardo, C.P. (2002). Er:YAG laser effects on enamel occlusal fissures: An in vitro study. J. Clin. Laser Med. Surg. 20, 27-35.

13. de Andrade, L.E.H., Pelino, J.E.P., Lizarelli, R.F.Z., Bagnato, V.S., and de Oliveira, O.B., Jr. (2007). Caries resistance of lased human enamel with Er:YAG laser - morphological and ratio $\mathrm{Ca} / \mathrm{P}$ analysis. Laser Phys. Lett. 4, 157-162.

14. Marraccini, T.M., Bachmann, L., Wigdor, H.A., Walsh, J.T. Jr., Stabholtz A., and Zezell D.M. (2005). Morphological evaluation of enamel and dentin irradiated with $9.6 \mu \mathrm{m} \mathrm{CO} 2$ and $2.94 \mu \mathrm{m}$ Er:YAG lasers. Laser Phys. Lett. 2, 551-555.

15. Apel, C., Birker, L., Meister, J., Weiss, C., and Gutknecht, N. (2004). The caries-preventive potential of subablative Er:YAG and Er:YSGG laser radiation in an intraoral model: a pilot study. Photomed. Laser Surg. 22, 312-317.

16. Liu, J.F., Liu, Y.Y., and Stephen H.C.Y. (2006). Optimal Er: YAG laser energy for preventing enamel demineralization. J. Dent. 34, 62-66.

17. Rodríguez-Vilchis, L.E., Contreras-Bulnes, R., SánchezFlores I., and Samano E.C. (2010). Acid resistance and structural changes of human dental enamel treated with Er:YAG laser. Photomed. Laser Surg. 28, 207-211.

18. Watari, F. ( 2001). Compositional and morphological imaging of $\mathrm{CO}_{2}$ laser irradiated human teeth by low vacuum SEM, confocal laser scanning microscopy and atomic force microscopy. J. Mater. Sci. Mater. Med. 12,189-194.

19. Wang, L., Ruikang, T., Bonstein, T., Orme, C. A., Bush, P. J., and Nancollas, G. H. (2005). A new model for nanoscale enamel dissolution. J. Phys. Chem. B 109, 999-1005.

20. Pan, H., Tao, J., Yu, X., Fu, L., Zhang, J., Zeng, X., Xu, G., and Tang, R. (2008). Anisotropic demineralization and oriented assembly of hydroxyapatite crystals in enamel: smart structures of biominerals. J. Phys. Chem. B 112, 7162-7165.

21. Watari, F. J. (2005). In situ quantitative analysis of etching process of human teeth by atomic force microscopy. J.Electron. Microsc. 54, 299-308.

22. Mine, A., Yoshida, Y., Suzuqui, K., Nakayama, Y., Yatani, H., and Kuboki, T. (2006). Spectroscopic characterization of enamel surfaces irradiated with Er:YAG laser. Dent. Mater. J. 25, 214-218.

23. Liu, Y.Y., and Hsu, C.Y.S. (2007). Laser-induced compositional changes on enamel: A FT-Raman study. J Dent. 35, 226-230.

24. Ryan, V., Hart, T. R., and Schiller, R. (1980). Size determination of streptococcus mutans 10449 by laser light scattering. Biophys J. 31, 313-324.

25. Secilmis, A., Usumez, A., Usumez, S., and Berk, G. (2010). Evaluation of mineral content of enamel prepared by erbium, chromium:yttrium-scandium-gallium-garnet laser. Lasers Med Sci. 25, 467-472.

26. Young, R.A. (1974). Implications of atomic substitutions and other, structural details in apatites. J. Dent. Res. 53, 193-203.

Address correspondence to:

Rosalía Contreras-Bulnes

Centro de Investigación y Estudios Avanzados en Odontología

Facultad de Odontología de la Universidad Autónoma del Estado de México

Jesús Carranza Esq. Paseo Tollocan Col. Universidad

Toluca, Estado de México México. C.P. 50130

E-mail: rcb0209@yahoo.com.mx or rcb@uaemex.mx 